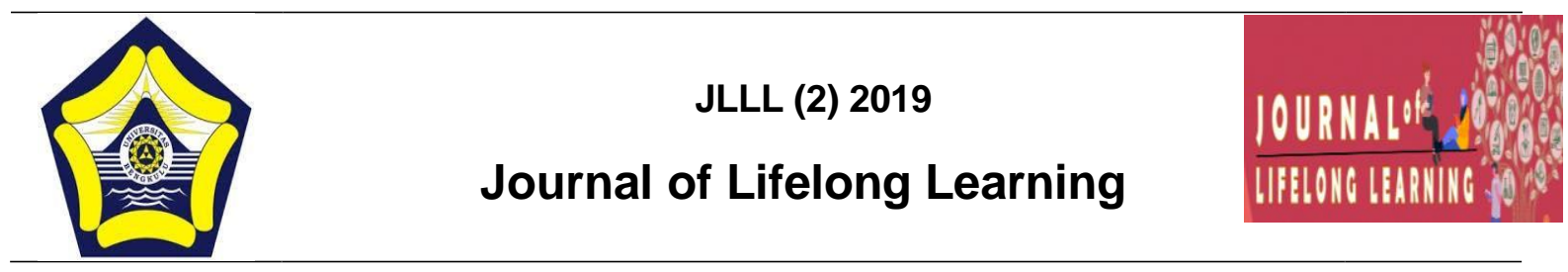

\title{
UPAYA PENGELOLA USAHA PEMBUATAN TEMPE LELA JAYA DALAM MENINGKATKAN KUALITAS PRODUK
}

\author{
Fera Sari ${ }^{1}$, Agus Rahmad ${ }^{2}$, Suardi ${ }^{3}$ \\ ${ }^{1}$ Nonformal Education, University of Bengkulu, Indonesia, feraindahsari@gmail.com \\ ${ }^{2}$ Nonformal Education, University of Bengkulu, Indonesia, aquszainal@gmail.com \\ 3 Nonformal Education, University of Bengkulu, Indonesia, suardi.jasma@ gmail.com
}

\begin{abstract}
The perpose of thi is research is to know the effort of management manufarturing business lela jaya tempe at home industry to increase family economi in manna south bengkulu. The is research lising quatitative reseach metode. To guarintee the validity of data. The researcher take triagulation of researcher subject and collecting data technique. Based on the research goal and the discussion can be concloded 1) in the improving a product guaity there are same that should be considorod, starting from row material selections production process until the packaging. Which are the row materias that hase ehoorod is a good row materials and prioritizing taste to make a good product and can fullfilling costumer needed. 2) merketing strategy of the product according to needed and desire of target marker. Aso give the sahsfadon of the coshimer. The manager of tempe lela jaya used marketing techic koitc obseroe kargot market needed by selling the product to restourant, vegetable shop, greengrocer and fried food seller. Which are in Manna Bengkulu Selatan and product quality guarantee the manager aso give not risk to the seller. The most important is the satifaction of the costomeri. 3) financial anaysis that used bby the manager of tempe tela jaya business is a simple entry which us used to nolice all of income and oatcome to know disadoentages or aduentager that obtained by the business. 4) the obstacles is weather conditions beside at the thing that can be manager support easy acces to get the material and easly production process.
\end{abstract}

Keywords : product quality, strategy 


\section{PENDAHULUAN}

Dalam mencapai kebutuhan pembangunan masyarakat, pemerintah mengembangkan 3 sistem pendidikan nasional di Indonesia. Dalam Undang-undang No. 20 Tahun 2003 tentang jenis pendidikan terbagi menjadi 3 (tiga) yaitu: 1) pendidikan formal adalah jalur pendidikan yang terstruktur dan berjenjang yang terdiri dari pendidikan dasar, pendidikan mennengah dan pendidikan tinggi, 2) pendidikan Non Formal adalah jalur pendidikan yang dilaksanakan di luar pendidikan formal yang dilaksanakan secara terstruktur dan berjenjang, dan 3) pendidikan informal adalah jalur pendidikan yang dilaksanakan di dalam dan lingkungan sekitar.Menurut Archibald Callaway dalam Marzuki, Saleh (2012: 99), pendidikan luar sekolah sebagai suatu bentuk kegiatan belajar yang berlangsung diluar sekolah dan universitas. Sedangkan menurut Sentoso S. Hamijoyo dalam Marzuki, Saleh (2012: 105), pendidikan luar sekolah sebagai kegiatan pendidikan yang dilakukan secara terorganisasikan, terencana di luar system persekolahan, yang bertujuan kepada individu ataupun kelompok dalam masyarakat untuk meningkatkan kualitas hidupnya.

Terdapat sebuah keluarga di Jalan Siaga 2 Manna Bengkulu Selatan yang memiliki industri rumah tangga (home industry) "tempe lela jaya".di mana dalam hal ini suami istri Bapak Ahmad Soim dan Ibu Desliti pendiri sekaligus pengelola industri rumah tangga (home industry) tersebut, awal mulanya usaha ini berdiri hanya dikelola oleh suami istri Bapak Ahmad Soim dan Ibu Desiti saja di mana tempat produksi pembuatan tempe dilakukan di sebuah rumah kontrakan sehingga hasil produk yang dihasilkan utuk di pasarkan masih terbatas. Tetapi, dengan kesabaran dan kemauan belajar serta kemampuan (skill) yang dimiliki, home industrytempe lela jaya ini dapat berkembang, hingga saat ini pengelola home industry sudah dapat memproduksi tempe lela jaya di Rumah miliknya sendiri dan mempekerjakan para tenaga kerjanya yaitu keluarga terdekat/teman-temannya untuk bergabung dalam memajukan bisnis usaha industri rumah tangga (home industry) tersebut. Home industry ini berdiri pada tahun 1985, dengan jumlah pekerja sebanayak 3 orang. Home industry tempe lela jaya ini dapat memproduksi 400 batang tempe perhari. Selain itu, keuntungan yang diperoleh home industrytempe lela jayasetiap bulannya mencapai Rp. 30.000.000,-. Hasil dari produksi tempe lela jaya ini sudah dipasarkan keberbagai daerah di Bengkulu Selatan mulai dari pasar ampera, pasar kutau, rumah makan, penjual gorengan.

Dilihat dari latar belakang masalah maka permasalahan yang diangkat dalam penelitian ini adalah: 1)bagaimana upaya pengelola untuk meningkatkan kualitas produk tempe lela jaya, 2) strategi pemasaran yang dilakukan oleh pngelola dalam meningkatkan kualitas produk, 3) analisis keuangan yang digunakan dalam meningkatkan kualitas produk, 4)faktor pendukung dan penghambat dalam meningkatkan kualitas produk tempe lela jaya.

1. Konsep Pendidikan Luar Sekolah (PLS) merupakan konsep yang muncul dalam studi pendidikan. Peraturan pemerintah Tahun 1991 ayat 1 dinyatakan bahwa pendidikan luar sekolah (PLS) adalah pendidikan yang diselenggarakan di luar sekolah baik yang dilembagakan maupun yang tidak dilembagakan. (1992:11) 
2. Konsep kewirausahaan menurut Salim siagian, pandji (2005: 27-28), mengemukakan bahwa "kewirausahaan adalah semangat, perilaku dan kemampuan untuk memberikan tanggapan yang positif terhadap peluang memperoleh keuntungan untuk diri sendiri dan atau pelayanan yang lebih baik pada pelanggan/masyarakat dengan selalu berusaha mencari pelanggan lebih banyak dan melayani pelanggan lebih baik, serta menciptakan dan menyediakan produk yang lebih bermanfaat dan menerapkan cara kerja yang lebih efisien, melalui keberanian mengembil resiko, kreativitas dan inovasi serta kemampuan manajemen".

3. Konsep industri rumah tangga Menurut S.R. Parker, dkk (2009:92) home industri/ industri rumah tangga bahasa latin industria yang berarti keterampilan dan penuh sumber daya. Sebenarnya manusia bersifat industrial, karena manusia senantiasa menggunakan alat-alat untuk mendapatkan makanan dan memenuhi kebutuhan.

4. Konsep produksi Menurut Rudiharjo (2001) dalam Anoraga Pandji (2005:249) mengatakan bahwa instilah "produksi” tampaknya berkonotasi sebagai organisasi produk, oleh karena itu istilah yang lebih umum, yaitu "operasi” disubstitusikan untuk menegaskan dasar umum di bidang ini..

5. Konsep strategi pemasaran usaha Mnurut Philip Kotler dalam Anoraga Pandji (2005:181) mengatakan bahwa konsep pemasaran adalah kunci mencapai tujuan organisasi yang terdiri dari penentuan kebutuhan dan keinginan pasar sasaran serta memberikan kepuasan yang diharapkan secara lebih efektif dan efisien dibanding pesaing.

6. Tempe adalah jenis makanan yang menjadi ciri khas negara indonesia yang kini telah diketahui banyak orang di dunia. Tempe sendiri dibuat dengan bahan kedelai yang dijadikan baha baku dalam proses pembuatan menggunakan proses fermentasi dengan menggunakan ragi. Rasa yang dimiliki tempe sangat enak lezat dan nikmat

\section{METODE}

Penelitian ini menggunakan metode penelitan kualitatif. Pada penelitian ini, terdapat empat orang subjek yaitu bapak Ahmad Soim sebagai pengelola usaha tempe lela jaya, ibu Desliti sebagai pengelola usahat pembuatan tempe, bapak Sirhan sebagai pencuci sekaligus perebus kacang kedelai dan Suwandi sebagai pembungkus tempe. Tempat penelitian ini beralamatkan di jalan Siaga 2 No 6 Manna Bengkulu Selatan. Teknik pengumpulan data menggunakan wawancara, observasi dan dokumentasi. Teknik analisis data dengan reduksi data, penyajian data dan penarikan kesimpulan. Pemeriksaan keabsahan dengan teknik triangulasi mulai dari triangulasi subjek, triangulasi waktu dan triangulasi teknik. 


\section{HASIL DAN PEMBAHASAN}

Berdasarkan temuan dilapangan dengan pengumpulan data melalui hasil wawancara, observasi dan dokumentasi, penulis dapat mengambil kesimpulan bahwa:

1. Dalam meningkatkan suatu kualitas produk ada beberapa hal yang harus deperhatikan mulai dari pemilihan bahan baku, proses produksi hingga ke pengemasan dimana bahan baku yang dipilih adalah bahan baku yang baik dan mengutamakan soal rasa agar mendapatkan hasil produk yang baik dan dapat memenuhi kebutuhan konsumen.

2. Strategi pemasaran hasil dari produksi sesuai dengan kebutuhan dan keinginan pasar sasaran serta memberikan kepuasan kepada konsumen. Pengelola usaha tempe lela jaya telah melakukan teknik pemasaran dengan melihat kebutuhan dan sasaran pasar dengan menjual produk ke pada rumah makan, penjual sayur dan penjual gorengan yang ada di daerah Manna Bengkulu Selatan dan menjamin dari kualitas produknya. Pengelola juga tidak memberikan resiko pada penjualnya yang penting kepuasan terhadap konsumen..

3. Analisis keuangan yang digunakan oleh pengelola usaha Tempe Lela Jaya adalah dalam bentuk pembukuan yang sederhana dinama pembukuan tersebut digunakan untuk mencatat semua pemasukan dan pengeluaran yang dilakukan dengan tujuan agar tidak terjadinya kerugian oleh pengelola.

4. Faktor penghambat pengelola adalah keadaan iklim (cuaca). Selain itu, yang menjadi faktor pendukung pengelola adalah mudahnya memperoleh bahan dan proses produksi produksi yang mudah.

\section{PENUTUP \\ KESIMPULAN}

Berdasarkan temuan penelitian dan pembahasan dapat diambil kesimpulan yaitu: Hasil penelitian menemukan bahwa dalam meningkatkan kualitas produk ada bebrapa yang harus di perhatikan mulai dari bahan baku sampai ke proses pengemasan, strategi yang digunakan dalam produksi mulai dari pemasaran, pengelola menggunakan analisis keuangan agar tidak trjadi kerugian dalam pengeluaran dan pemasukan uang dan faktor yang mnjdi pendukung bahan bakunya mudah dicari sedagkan faktor penghambatnya pada cuaca .

\section{REFERENSI}

Anoraga, Pandji. (2005). Pengantar Bisnis. Jakarta: PT.Rineka Cipta

Departemen Pendidikan Nasional.(2003).Kamus Besar Bahasa Indonesia. Jakarta: Balai Pustaka Dianawati.Ajen.(2007). Peluang Usaha Rumahan Yang Menguntungkan. Jakarta: PTTransMedia Haliza,Winda, Endang Yuli Purwani, and Ridwan Thahir.'”pemanfaatan kacang kacang lokal sebagai substitusi bahan baku tempe.' Buletin Teknologi Pasca Panen 3.1 (2016): 1-8

Harimurti Subanar, (2001), Manajemen Usaha Kecil, BPFE, Yogyakarta. 
Mulyadi. (1986). Akuntansi Biaya :Penentuan Harga Pokok dan Pengendalian Biaya. Edisi Ketiga. BPFE.Yogyakarta.

Purwaningsih, Eko. Cara Pembuatan Tempe dan Manfaat Kedelai. Ganeca $\quad$ Exact, (2007)

S.R. Parker, dkk. (2009).Sosiologi Industri. Jakarta: PT. BinaAksara

Sugiyono.(2013). Metode Penelitian Kualitatif Kuantitatif R\&D. Bandung CV. ALFABETA

Undang-Undang RI NO.20 tahun(2003), Tentang System Pendidikan Nasional, Jakarta

Undang-Undang RI No. 20 Tahun(2003). Tentang Sistem Pendidikan Nasional. Jakarta :Cemerlang 